\title{
Sensitive and Selective Detection of Hydrogen Using YSZ- based Sensor with Zn-Ta-based Oxide Sensing-electrode
}

\author{
Sri Ayu Anggraini ${ }^{1}$, Michael Breedon ${ }^{2,3}$, Norio Miura ${ }^{3}$ \\ ${ }^{1}$ Interdisciplinary Graduate School of Engineering Sciences, Kyushu University, 6-1 Kasuga Koen, \\ Kasuga city, Fukuoka, 816-8580, Japan \\ 2 Japan Society for the Promotion of Science, 8 Ichibancho, Chiyoda-ku, Tokyo, 102-8472, Japan \\ ${ }^{3}$ Art, Science and Technology Center for Cooperative Research (KASTEC), Kyushu University, \\ 6-1 Kasuga Koen, Kasuga city, Fukuoka, 816-8580, Japan \\ Corresponding author: miurano@astec.kyushu-u.ac.jp
}

\begin{abstract}
An yttria-stabilized zirconia (YSZ)-based sensor utilizing a Zn-Ta-based oxide sensing electrode (SE) is reported herein as being capable of generating sensitive and selective response toward hydrogen $\left(\mathrm{H}_{2}\right)$. The addition of 84 wt.\% $\mathrm{Ta}_{2} \mathrm{O}_{5}$ into $\mathrm{ZnO}$ brought about the highest response toward $\mathrm{H}_{2}$, when compared with other examined $\mathrm{Zn}$-Ta-based oxide SE materials. After a stabilization period of about 50 days, the sensor exhibited a stable and high sensitivity ( $\Delta$ emf) of approximately $-600 \mathrm{mV}$ toward $100 \mathrm{ppm} \mathrm{H}_{2}$ and low cross-sensitivity towards other examined gases $(< \pm 80 \mathrm{mV})$ at $500^{\circ} \mathrm{C}$ under humid operating conditions $\left(20\right.$ vol. $\% \mathrm{O}_{2}$ and 5 vol. $\% \mathrm{H}_{2} \mathrm{O}$ ). An almost linear relationship between sensitivity and $\mathrm{H}_{2}$ concentration (10-100 ppm) was observed for the developed sensor.
\end{abstract}

Keywords: Gas sensors, Hydrogen, YSZ, Potentiomentric, $\mathrm{ZnO}, \mathrm{Ta}_{2} \mathrm{O}_{5}$

\section{Introduction}

Existing renewable energy such as wind or solar energy offerings are static systems which lack of portability, limiting potential applications; unlike $\mathrm{H}_{2}$ which is compressible. $\mathrm{H}_{2}$ has been touted as a potential substitute where petroleum is currently used, particularly when used with fuel cell driven vehicles and power generators. However, since $\mathrm{H}_{2}$ is a colorless, odorless gas, with a low ignition energy $(0.02$ $\mathrm{mJ})$, combined with a lower explosive limit of 4 vol. \% has made it poses an explosive risk [1]. This has made the utilization of $\mathrm{H}_{2}$ difficult as it poses a serious risk. Considering this, the demand for a device that can detect $\mathrm{H}_{2}$ sensitively and selectively, is of great interest for safety monitoring applications. For high temperature applications, YSZ-based gas sensors have been acknowledged as one of the leading candidates for reliable and highperformance gas sensors during several decades, due to their good thermal and mechanical stability under harsh working conditions.

An attempt to utilize $\mathrm{ZnO}$ as a sensing electrode material for mixed-potential type YSZbased sensors was investigated more than ten years ago [2]. However, the high response toward hydrogen was also accompanied by responses toward other examined gases. Two years later, it was reported that the addition of
$\mathrm{Ta}_{2} \mathrm{O}_{5}$ into another metal oxide could yield selective catalytic properties [3]. Furthermore, the addition of $\mathrm{Ta}_{2} \mathrm{O}_{5}$ into SEs has been proven to improve the selectivity of a potentiometric sensor [4], and $\mathrm{Ta}_{2} \mathrm{O}_{5}$-based materials have been reported to give high sensitivity toward $\mathrm{H}_{2}$ [5]. Hence, $\mathrm{Ta}_{2} \mathrm{O}_{5}$ was added into $\mathrm{ZnO}$ in this study and the sensing performances of the developed YSZ-based sensor using a Zn-Tabased oxide SE were examined.

\section{Experimental}

The sensor was fabricated using a hemispherically terminated $\mathrm{YSZ}$-tube $\left(8 \mathrm{~mol} . \% \mathrm{Y}_{2} \mathrm{O}_{3}\right.$ doped $\mathrm{ZrO}_{2}$, Nikkato, Japan). Recently, our group has proposed the utilization of an intermediate layer of YSZ, in order to improve mechanical stability at the interface between SE and YSZ solid electrolyte. Therefore, an intermediate YSZ layer between the SE and the YSZ solid electrolyte was also fabricated here. In this process, YSZ powder (Tosoh Corp., Japan) was mixed with an organic binder ( $\alpha$ terpineol). The resulting paste was painted onto the surface of YSZ tube.

The sensing electrode material was fabricated by mixing commercial $\mathrm{ZnO}$ powder (Konjundo Chemical Lab., Japan) with $\mathrm{Ta}_{2} \mathrm{O}_{5}$ powder (Konjundo Chemical Lab., Japan) in a mortar. An organic binder ( $\alpha$-terpineol) was added into the mixed powder, making a uniform paste. 
This paste was applied onto the surface of YSZ layer, which had been previously painted onto the YSZ tube, forming a $4 \mathrm{~mm}$-wide band. The reference electrode (RE) was made by applying Pt paste (Tanaka, Kikinzoku, Japan) on the inner surface of the end of the YSZ tube. Subsequently, the assembled sensor was sintered at $1200 \circ \mathrm{C}$ for $2 \mathrm{~h}$ in air to form the SE and the RE.

The gas sensing characteristics of the fabricated sensors were evaluated at an operational temperature of $500^{\circ} \mathrm{C}$ under humid conditions (5 vol.\% $\mathrm{H} 2 \mathrm{O})$. The potential difference between SE and Pt/air-RE was measured using a digital electrometer (R8240, Advantest, Japan), as a sensing signal. The crystal structure of the SE layers was analyzed with an X-ray diffractometer (XRD, RINT 2100VLR/PC, Rigaku, Japan) with $\mathrm{Cu} \mathrm{K} \alpha$ radiation.

\section{Results and Discussions}

Figure 1 shows the preliminary test results for the sensor utilizing ZnO-SEs with different additions of Ta2O5. As shown in this figure, the sensor using $\mathrm{ZnO}(+84$ wt.\% $\mathrm{Ta2O5})-\mathrm{SE}$ showed the most sensitive response toward $400 \mathrm{ppm} \mathrm{H} 2(\Delta \mathrm{emf}=-250 \mathrm{mV})$ when operated at $500 \circ \mathrm{C}$ under the humid conditions (5 vol.\% $\mathrm{O} 2+5$ vol. $\% \mathrm{H} 2 \mathrm{O}$ ), in comparison with other sensors using SEs with different percentage additions of $\mathrm{Ta} 2 \mathrm{O} 5$, as well as the parental $\mathrm{ZnO}-$ and Ta2O5-SE. The sensor could generate not only a sensitive response toward $\mathrm{H} 2$, but also a relatively selective one, since the response toward other examined gases were also found to be low (e.g., $\Delta$ emf towards $C O=-$ $45 \mathrm{mV}, \mathrm{C} 3 \mathrm{H} 8=-9 \mathrm{mV}, \mathrm{C} 3 \mathrm{H} 6=-73 \mathrm{mV}, \mathrm{NOx}<$ $\pm 20 \mathrm{mV})$.

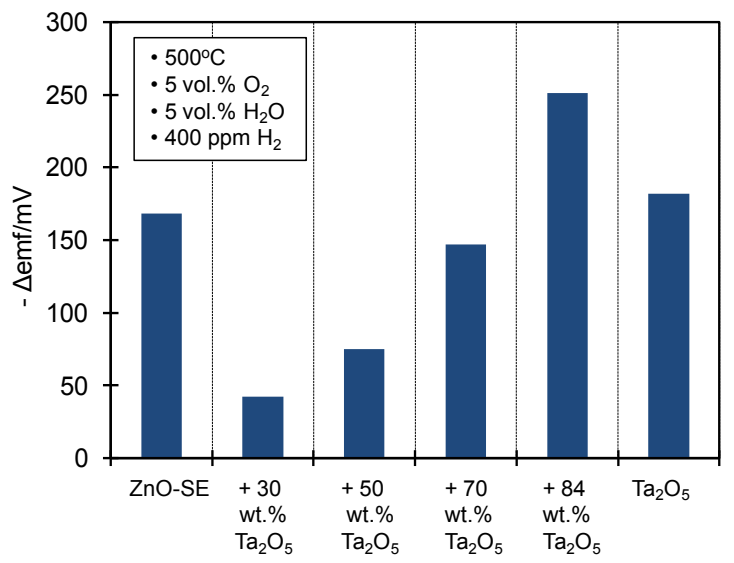

Fig. 1 The comparison of $\mathrm{H} 2$ response at $5000 \mathrm{C}$ of sensors utilizing $\mathrm{ZnO}$ with increasing addition and/or pure Ta2O5, as SE.

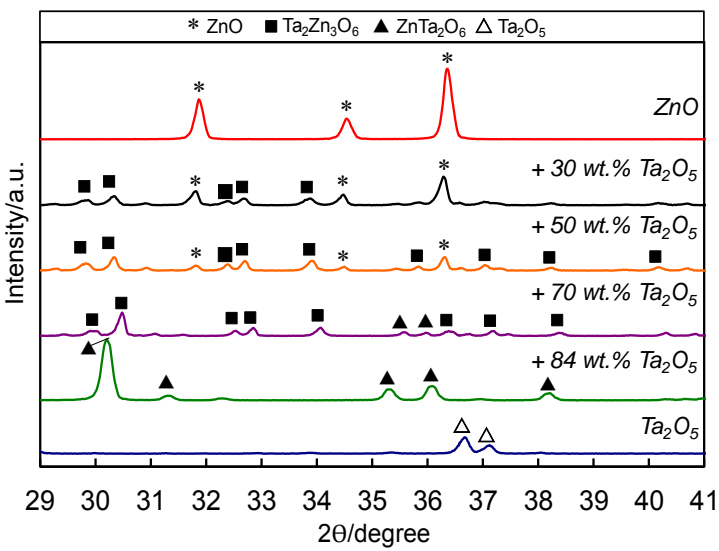

Fig. 2 The XRD patterns of ZnO-SE with different additions of Ta2O5 after sintering at $12000 \mathrm{C}$ for $2 h$.

The XRD pattern comparison of $\mathrm{ZnO}$ with different additions of $\mathrm{Ta} 2 \mathrm{O} 5$ and pure Ta2O5 is presented in Fig. 2. It is seen that the addition of $\mathrm{Ta} 2 \mathrm{O} 5$ to $\mathrm{ZnO}$ with increasing ratio resulted in a mixture of crystal phases and stoichiometries. The addition of $30 \mathrm{wt} \% \%$ Ta2O5 was confirmed to form a mixture that was identified as being in good agreement with $\mathrm{ZnO}$ (JCPDS no.: 36-1451) and Ta3Zn2O6 (JCPDS no.20-1237). The XRD peaks for the $\mathrm{ZnO}(+50$ wt.\% Ta2O5) sample confirmed the formation of the similar mixture to the previous sample. This would explain the similar $\mathrm{H} 2$ response that both $\mathrm{SEs}$ generated. When the addition of $\mathrm{Ta} 2 \mathrm{O} 5$ into $\mathrm{ZnO}$ was raised to $70 \mathrm{wt} . \%$, the observed peaks were found to be in good agreement with a mixture of ZnTa2O6 (JCPDS no.: 39-1484) and $\mathrm{Ta} 3 \mathrm{Zn} 2 \mathrm{O} 6$, despite the occurrence of some minor peak shifting. However, when 84 wt. $\%$

$\mathrm{Ta}_{2} \mathrm{O}_{5}$ was added into the $\mathrm{ZnO}$, the resulting compound was identified as being single phase and in good agreement with $\mathrm{ZnTa}_{2} \mathrm{O}_{6}$.

Tab. 1: The cross sensitivity of the sensor utilizing $\mathrm{ZnO}(+84$ wt.\% Ta2O5)-SE toward different gases at $5000 \mathrm{C}$ under humid conditions (20 vol. $\% \mathrm{O} 2+5$ vol. $\% \mathrm{H} 2 \mathrm{O}$ ).

\begin{tabular}{|c|c|}
\hline $\begin{array}{c}\text { Gas } \\
\text { (100 ppm) }\end{array}$ & $\begin{array}{c}\text { Sensitivity } \\
(\mathbf{\Delta e m f} / \mathbf{~ m V} \mathbf{)}\end{array}$ \\
\hline $\mathrm{H}_{2}$ & -598 \\
\hline $\mathrm{CO}$ & -11 \\
\hline $\mathrm{CH}_{4}$ & -13 \\
\hline $\mathrm{C}_{3} \mathrm{H}_{8}$ & -9 \\
\hline $\mathrm{C}_{3} \mathrm{H}_{6}$ & -3 \\
\hline $\mathrm{NO}$ & -17 \\
\hline $\mathrm{NO}_{2}$ & 25 \\
\hline $\mathrm{NH}_{3}$ & -38 \\
\hline
\end{tabular}


The developed sensor was then maintained at $500^{\circ} \mathrm{C}$ to assess the long-term stability. After a stabilization period of 50 days, the sensor response (emf) toward $\mathrm{H}_{2}$ was found to increase largely from $-250 \mathrm{mV}$ to $-830 \mathrm{mV}$. Furthermore, the response stabilized at around $-830 \mathrm{mV}$ after the 50th day. This increase in $\mathrm{H}_{2}$ sensitivity is believed to be due to both of the decreased catalytic activity to the cathodic reaction of $\mathrm{O}_{2}$ and the increase in catalytic activity to the anodic reaction of $\mathrm{H}_{2}$.

For environmental monitoring applications, the sensor was examined also in 20 vol. $\% \mathrm{O}_{2}$ and the cross sensitivity toward different gases is given in Table 1. As can be seen from this result, the developed sensor is capable of generating a sensitive and selective response ( $\Delta$ emf) toward 100 ppm $\mathrm{H}_{2}$ (about $-600 \mathrm{mV}$ ) with smaller or negligible responses toward other examined gases.

In addition, the dependency of sensitivity on the $\mathrm{H}_{2}$ concentration was examined. The almost linear relationship between the sensitivity and $\mathrm{H}_{2}$ concentration was observed in the low concentration range $(<100 \mathrm{ppm})$. On the other hand, in the higher $\mathrm{H}_{2}$ concentration range (>100 ppm), a linear relationship was observed between sensitivity and concentration on logarithmic scale.

\section{Conclusions}

A systematic investigation of effect of $\mathrm{Ta}_{2} \mathrm{O}_{5}$ addition into $\mathrm{ZnO}-\mathrm{SE}$ on the resulting crystal structure as well as gas sensing performance was performed. It was observed that, the addition of 84 wt. $\% \mathrm{Ta}_{2} \mathrm{O}_{5}$ into $\mathrm{ZnO}$ formed an entirely new phase of $\mathrm{ZnTa}_{2} \mathrm{O}_{6}$. The sensor using $\mathrm{ZnTa}_{2} \mathrm{O}_{6}$-SE was capable of generating highest response toward $\mathrm{H}_{2}$ when compared with other SEs with different $\mathrm{Ta}_{2} \mathrm{O}_{5}$ additions. The study revealed that after 50 days, the response of the sensor using $\mathrm{ZnTa}_{2} \mathrm{O}_{6}-\mathrm{SE}$ toward $400 \mathrm{ppm} \mathrm{H}_{2}$ was stabilized at around $840 \mathrm{mV}$, and was accompanied by negligible response toward other gases $(\Delta \mathrm{emf}<80 \mathrm{mV})$. The sensitivity was found to have an almost linear relationship with $\mathrm{H}_{2}$ concentration in the range of 10-100 ppm.

\section{Acknowledgements}

This work was supported partially by the Kyushu University Global-COE program and Grant-in-aid for Scientific Research (B) (22350095) and for JSPS fellows (22-0353).

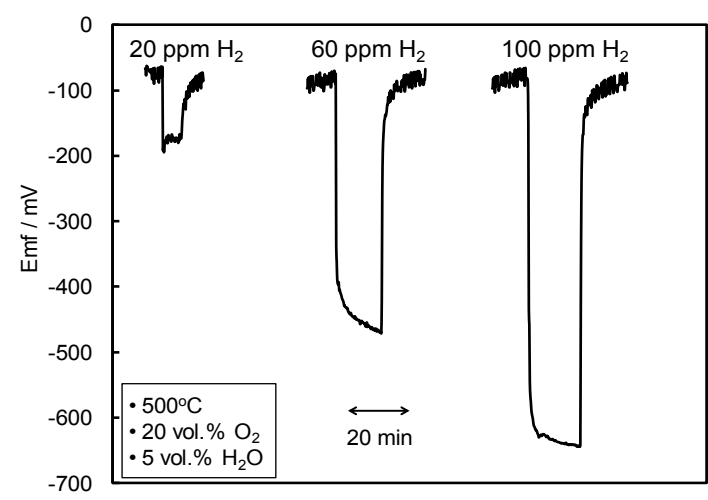

Fig. 3 The response transients of the sensor utilizing $\mathrm{ZnO}(+84$ wt.\%Ta2O5)-SE toward 20, 60 and 100 ppm H2 ; at an operating temperature of $5000 \mathrm{C}$ under humid conditions.

Figure 3 shows the response transients of the sensor utilizing $\mathrm{ZnO}\left(+84\right.$ wt.\% $\left.\quad \mathrm{Ta}_{2} \mathrm{O}_{5}\right)$-SE toward 20,60 and $100 \mathrm{ppm} \mathrm{H}_{2}$ at $500^{\circ} \mathrm{C}$ under humid conditions (5 vol. $\% \mathrm{H}_{2} \mathrm{O}+20$ vol. $\% \mathrm{O}_{2}$ ). The $90 \%$ response time $\left(\mathrm{t}_{90}\right)$ to $100 \mathrm{ppm} \mathrm{H}_{2}$ for the sensor was approximately $70 \mathrm{~s}$. Considering these obtained sensing performances of the developed sensor utilizing $\mathrm{ZnO}\left(+84\right.$ wt. $\left.\% \mathrm{Ta}_{2} \mathrm{O}_{5}\right)-\mathrm{SE}$, this device could be considered as one of prospective candidates for $\mathrm{H}_{2}$ sensor capable of operating at high temperatures

\section{References}

[1] T. Hubert, L. Boon-Brett, G. Black, U. Banach, Hydrogen sensors - A review, Sens. Actuators B, 157, 329-352 (2011); doi: 10.1016/j.snb.2011.04.070.

[2] N. Miura, T. Raisen, G. Lu, N. Yamazoe, Highly selective $C O$ sensor using stabilized zirconia and a couple of oxide electrodes, Sens. Actuators B, 47, 84-91 (1998); doi:10.1016/S09254005(98)00053-7.

[3] T. Ushikubo, Recent topics of research and development of catalysis by niobium and tantalum oxides, Cat. Today, 57, 331-338 (2000); doi:10.1016/S0920-5861(99)00344-2.

[4] L. Chevallier, E. Traversa, E. Di Bartolomeo, Propene detection at high temperature using highly sensitive non-nernstian electrochemical sensors based on $\mathrm{Nb}$ and $\mathrm{Ta}$ oxides, $J$. Electrochem. Soc.,157(11), J386-J391 (2010) ; doi:10.1149/1.3486080.

[5] J. Zosel, G. Schiffel, F. Gerlach, K. Ahlborn, U. Sasum, V. Vashok, U. Guth, Electrode materials for potentiometric hydrogen sensors, Solid State lonics, 177, 2301-2304 (2006) ; doi:10.1016/j.ssi.2006.01.004. 